\title{
ON GENERALIZED DERIVATIONS AND COMMUTATIVITY OF ASSOCIATIVE RINGS
}

\author{
GuRninder S. SANDHU \\ Department of Mathematics, Patel Memorial National College \\ Rajpura-140401, Punjab, India \\ e-mail: gurninder_rs@pbi.ac.in \\ DEEPAK KuMAR \\ Department of Mathematics, Punjabi University \\ Patiala-147002, Punjab, India \\ e-mail: deep_math1@yahoo.com \\ AND \\ Bijan Davvaz \\ Department of Mathematics \\ Yazd University, Yazd, Iran \\ e-mail: davvaz@yazd.ac.ir
}

\begin{abstract}
Let $\mathcal{R}$ be a ring with center $Z(\mathcal{R})$. A mapping $f: \mathcal{R} \rightarrow \mathcal{R}$ is said to be strong commutativity preserving (SCP) on $\mathcal{R}$ if $[f(x), f(y)]=[x, y]$ and is said to be strong anti-commutativity preserving (SACP) on $\mathcal{R}$ if $f(x) \circ f(y)=x \circ y$ for all $x, y \in \mathcal{R}$. In the present paper, we apply the standard theory of differential identities to characterize SCP and SACP derivations of prime and semiprime rings.
\end{abstract}

Keywords: generalized derivations, (semi)prime rings, generalized polynomial identities, Martindale ring of quotients.

2010 Mathematics Subject Classification: Primary 46J10, 16N20;

Secondary 16N60, 16W25.

\section{REFERENCES}

[1] S. Ali, V. De Filippis and M.S. Khan, Pair of derivations of semiprime rings with applications to Banach algebras, J. Algebra and Comp. Appl. 3 (2013) 01-13. 
[2] S. Ali and S. Huang, On derivations in semiprime rings, Algebra and Rep. Theory 15 (2012) 1023-1033. doi:10.1007/s10468-011-9271-9

[3] M. Ashraf and N. Rehman, On commutativity of rings with derivations, Results Math. 42 (2002) 3-8.

doi:10.1007/BF03323547

[4] M. Ashraf, N. Rehman and M.A. Raza, A note on commutativity of semiprime Banach algebras, Beitr Algebra Geom. 57 (2016) 553-560. doi:10.1007/s13366-015-0264-4

[5] K.I. Beidar, W.S. Martindale III and A.V. Mikhalev, Rings with generalized identities (Pure and Applied Mathematics, 196 Marcel Dekker, New York, 1996).

[6] K.I. Beidar, Rings with generalized identities III, Moscow Univ. Math. Bull. 33 (1978) 53-58.

[7] H.E. Bell and M.N. Daif, On commutativity and strong commutativity preserving maps, Canad. Math. Bull. 37 (1994) 443-447. doi:10.4153/CMB-1994-064-x

[8] H.E. Bell and N. Rehman, Generalized derivations with commutativity and anticommutativity conditions, Math. J. Okayama Univ. 49 (2007) 139-147.

[9] J. Bergen, I.N. Herstein and J. W. Kerr, Lie ideals and derivations of prime rings, J. Algebra 71 (1981) 259-267.

doi:10.1016/0021-8693(81)90120-4

[10] M. Bresar and C.R. Miers, Strong commutativity preserving maps of semiprime rings, Canad. Math. Bull. 37 (1994) 457-460. doi:10.4153/CMB-1994-066-4

[11] C.L. Chuang, GPIs having coeffiecients in Utumi quotient rings, Proc. Amer. Math. Soc. 103 (1988) 723-728.

doi:10.1090/S0002-9939-1988-0947646-4

[12] C.L. Chuang, Hypercentral derivations, J. Algebra 166 (1994) 34-71.

doi:10.1006/jabr.1994.1140

[13] C.L. Chuang, The additive subgroup generated by a polynomial, Israel J. Math. 59 (1987) 98-106. doi:10.1007/BF02779669

[14] Q. Deng and M. Ashraf, On strong commutativity preserving mappings, Result. Math. 30 (1996) 259-263. doi:10.1007/BF03322194

[15] T.S. Erickson, W.S. Martindale III and J. M. Osborn, Prime nonassociative algebras, Pacific J. Math. 60 (1975) 49-63.

doi:10.2140/pjm.1975.60.49 
[16] V. De Filippis and G. Scudo, Strong commutativity and Engel condition preserving maps in prime and semiprime rings, Linear and Multilinear Algebra 61 (2013) 917-938. doi:10.1080/03081087.2012.716433

[17] I.N. Herstein, A note on derivations, Canad. Math. Bull. 21 (1978) 369-370. doi:10.4153/CMB-1978-065-x

[18] I.N. Herstein, Center-like elements in prime rings, J. Algebra 60 (1979) 567-574. doi:10.1016/0021-8693(79)90102-9

[19] S. Huang, Generalized derivations of prime and semiprime rings, Taiwanese J. Math. 6 (2012) 771-776. doi:10.11650/twjm/1500406614

[20] S. Huang and B. Davvaz, Generalized derivations of rings and Banach algebras, Commun. Algebra 41 (2013) 1188-1194. doi:10.1080/00927872.2011.642043

[21] N. Jacobson, Structure of rings (Colloquium publications, vol. XXXVIII, Amer. Math. Soc. 190, Hope street, provindence, R.I., 1956).

[22] V.K. Kharchenko, Differential identities of prime rings, Algebra Logic 17 (1979) $155-168$. doi:10.1007/BF01670115

[23] C. Lanski, An Engel condition with derivation, Proc. Amer. Math. Soc. 118 (1993) $731-734$. doi: $10.2307 / 2160113$

[24] T.K. Lee, Generalized derivations of left faithful rings, Comm. Algebra 27 (1999) 4057-4073. doi:10.1080/00927879908826682

[25] T.K. Lee, Semiprime rings with differential identities, Bull. Inst. Math. Acad. Sin. 20 (1992) 27-38.

[26] P.H. Lee and T.L. Wong, Derivations cocentralizing Lie ideals, Bull. Ins. Math. Acad. Sin. 23 (1995) 1-5.

[27] C.K. Liu and P.K. Liau, Strong commutativity preserving generalized derivations on Lie ideals, Linear and Multilinear Algebra 59 (2011) 905-915. doi:10.1080/03081087.2010.535819

[28] J. Ma, X.W. Xu and F.W. Niu, Strong commutativity preserving generalized derivations on semiprime rings, Acta Math. Sin. 24 (2008) 1835-1842. doi:10.1007/s10114-008-7445-0

[29] W.S. Martindale III, Prime rings satisfying a generalized polynomial identity, J. Algebra 12 (1969) 576-584. doi:10.1016/0021-8693(69)90029-5

[30] L. Oukhtite, Posner's second theorem for Jordan ideals in rings with involutions, Expo. Math. 29 (2011) 415-419. doi:10.1016/j.exmath.2011.07.002 
[31] G.S. Sandhu and D. Kumar, A note on derivations and Jordan ideals of prime rings, AIMS Math. 2 (2017) 580-585.

doi:10.3934/Math.2017.4.580

[32] X.W. Xu, The Power Values Properties of Generalized Derivations (Doctoral Thesis of Jilin University, Changchun, 2006).

Received 30 December 2018

Revised 10 Octover 2019

Accepted 24 January 2020 